\title{
Right Hepatic Duct
}

National Cancer Institute

\section{Source}

National Cancer Institute. Right Hepatic Duct. NCI Thesaurus. Code C33476.

The duct that drains bile from the right lobe of the liver into the common hepatic duct. 